\title{
Design, development, testing and validation of a Photonics Virtual Laboratory for the study of LEDs
}

Francisco Naranjo, Guadalupe Martínez, Ángel Pérez, Pedro Pardo

Francisco L. Naranjo, Guadalupe Martínez, Ángel Luis Pérez, Pedro J. Pardo, "Design, development, testing and validation of a Photonics Virtual Laboratory for the study of LEDs," Proc. SPIE 9289, 12th Education and Training in Optics and Photonics Conference, 92891T (17 July 2014); doi: $10.1117 / 12.2070561$

Event: 12th Education and Training in Optics and Photonics Conference, 2013, Porto, Portugal 


\title{
Design, development, testing and validation of a Photonics Virtual Laboratory for the study of LEDs
}

\author{
Francisco L. Naranjo*a, Guadalupe Martínez ${ }^{\mathrm{a}}$, Ángel Luis Pérez ${ }^{\mathrm{a}}$, Pedro J. Pardo ${ }^{\mathrm{a}}$ \\ ${ }^{a}$ Dept. of Physics, Faculty of Sciences, University of Extremadura, Avda. de Elvas s/n, Badajoz, \\ 06006 Spain
}

\begin{abstract}
This work presents the design, development, testing and validation of a Photonic Virtual Laboratory, highlighting the study of LEDs. The study was conducted from a conceptual, experimental and didactic standpoint, using e-learning and $\mathrm{m}$-learning platforms. Specifically, teaching tools that help ensure that our students perform significant learning have been developed. It has been brought together the scientific aspect, such as the study of LEDs, with techniques of generation and transfer of knowledge through the selection, hierarchization and structuring of information using concept maps. For the validation of the didactic materials developed, it has been used procedures with various assessment tools for the collection and processing of data, applied in the context of an experimental design. Additionally, it was performed a statistical analysis to determine the validity of the materials developed. The assessment has been designed to validate the contributions of the new materials developed over the traditional method of teaching, and to quantify the learning achieved by students, in order to draw conclusions that serve as a reference for its application in the teaching and learning processes, and comprehensively validate the work carried out.
\end{abstract}

Keywords: Photonic, virtual laboratory, LED, e-learning, didactics

\section{INTRODUCTION}

Currently there is a growing tendency to introduce information and communication technologies (ICT) in the teaching and learning processes of students, not only on the conceptual contents of the various teaching subjects, but also on the procedural content. This is due to the large amount of didactic materials that can be made using ICT. Among these materials, it stands out the great interest in the use of virtual laboratories, especially in scientific fields, since the importance of the acquisition of skills by students is more necessary in science subjects, such as physics in general or optics in particular. That is, laboratory practices are an essential educational resource in teaching experimental and technical disciplines, and they allow students to check their degree of assimilation of the theoretical contents. However, sometimes practice subjects carry some degree of difficulty for students in terms of understanding the experience. These difficulties can be referred either to the theoretical foundation of laboratory practices, the procedure or how to use the required equipment. Moreover, for different reasons real laboratories may not always be available to students, which imposes restrictions on student learning when developing the procedural content of the subjects. Another factor that may limit the use of real laboratories is the schedule, as the laboratory may not always be free for them to use. From this point of view, the tools available today can be used to improve accessibility to the experimental part of the subjects by creating virtual laboratory practices $[1,2,3,4,5,6]$.

In a previous work [7], our research group highlights the advantages of ICT instructional videos as tools to facilitate meaningful learning in our students, and stressed that the introduction of ICT in the teaching of experimental science is one of the most interesting stages of current teaching. This involves, for example, the introduction of new virtual platforms such as e-learning, m-learning and b-learning, with innovative teaching resources that promote meaningful learning in students. If we make an analysis of the tools related to virtual or remote laboratories, we find many resources in recent literature $[8,9,10,11,12,13,14]$.

Following this line of research, and based on some of our previous results $[15,16]$, in this work we have focused on the design, creation and implementation of teaching materials that motivate the student and promote constructivist learning when performing Photonics laboratory practices. These materials have brought together the science, such as the scientific

*naranjo@unex.es; grupoorion.unex.es

12th Education and Training in Optics and Photonics Conference, edited by

Manuel F. P. C. Martins Costa, Mourad Zghal, Proc. of SPIE Vol. 9289, 92891T

(C) 2014 SPIE, OSA, IEEE, ICO·doi: 10.1117/12.2070561

Proc. of SPIE Vol. 9289 92891T-1 
content of Photonics, with the use of techniques of generation and transfer of knowledge through the selection, hierarchization and structuring of information using concept maps. Concept maps are diagrams that represent organized knowledge. The theoretical foundation for concept maps relies on Ausubel's Assimilation Theory [17], and Novak's Theory of Learning [18]. A concept map consists of a graphical representation of a set of propositions about a topic, and every concept map answers to a focus question that clearly identifies the issue the concept map should help to resolve [19]. Our research group has applied concept maps as a teaching methodology in our assigned courses, in order to promote meaningful learning, and to enhance different learning strategies that transform information about the contents of a subject in knowledge [20]. In line with this approach, it has been shown [19] the statistically significant increase of learning obtained after the use by students of knowledge models based on concept maps. It has been validated that concept maps are very powerful educational tools to help students learn how to learn, when working with conceptual contents. Moreover, concept maps can be useful when working with procedural content, by creating laboratory practices procedural models based on concept maps [21]. These procedural models provide students new educational materials that allow learning to proceed, and conducting laboratory experiments both on real and virtual environments.

In this work, we propose the connection between concept maps, as base elements of procedural models, and instructional laboratory videos to study Photonics related content. Specifically, we have selected the contents of the Photonics practices to perform, and we have implemented training videos as base tools for the design and creation of a virtual laboratory, in order to facilitate students their training prior to the completion of the actual laboratory practices, or even substituting them in virtual learning platforms such as e-learning, b-learning or m-learning.

\section{METHODOLOGY}

\subsection{Objective: Creating a virtual laboratory based on instructional videos and concept maps}

The overall objective of this work has been to design, develop and validate educational materials using ICT, and deploy them on a virtual platform for the study of Photonics contents from a conceptual, experimental and didactic point of view. The experience has been focused on the development of concept maps conforming procedural models, and in the creation of instructional videos for a Virtual Laboratory.

To carry out the creation of the virtual laboratory with instructional videos, we have followed the following steps:

- Scientific review of contents: Selection of topics and objectives.

- Management and acquisition of additional laboratory equipment for the development of practices.

- Design of laboratory experiences: Development of practice manuals using procedural models, which show the specific objectives, the materials used, the procedure and how to display the results.

- Setup and completion of the actual laboratory practice and recording of the instructional video.

- Selection of the most suitable scenes to show students a comprehensive overview of the practice carried out.

- Video editing: selecting shots and combining them into sequences to create a finished instructional video.

- Development of animations and infographics to complement the real images shot in the laboratory and provide additional aid.

- Audio recording and soundtrack editing.

- Instructional video export in several media formats, compatible with different e-learning and m-learning platforms, to facilitate distribution.

The developed instructional videos are one of the foundations of the virtual laboratory, and are logically sequenced and structured, as in the real laboratory, to facilitate the inclusion of the objectives and procedures of the practice in question. In this way we can virtually display how to make the whole experience, as it is done in the actual optical laboratory. Addressing the practices in a sequential way in the instructional video allows optimizing available resources by not having all groups of students using the same physical material simultaneously. It optimizes as well the time available, allowing the realization of more complex experiences or a greater number of them. All the educational videos produced have a common structure. They begin with the title of the practice and a short introduction to place such practical experience in context of the course, and describe the basic theoretical concepts related to the experience that will be performed. It shows the objective of the experience and the material to be used, and emphasis is placed on the steps to 
carry it out. Finally, it indicates how the students should analyse and present data. That is, in this material is integrated the visualization of the experimental part of the practices and practice manual to adequately respond to the needs of the students when they implement the experimental procedure.

Regarding the use of concept maps and procedural models on virtual laboratory practices, we intend to focus on the content, foundations, objectives, materials, procedures, results and conclusions of the various experiments carried out in the different instructional videos, using the focus questions of the developed concept maps. In this stage, the teacher gave the student a concept map based on the practice that the student had to perform. This concept map gathers the title and objective of the practice to be carried out. Similarly, the teacher provides the student with the instructional video of the virtual laboratory, and the needed literature to cover the theoretical contents involved in the practice. Subsequently, students must complete the concept maps of the practice manual by adding materials, procedures and possible cross-links related to the theoretical foundations of the experience in question. At this stage, there is the possibility of structuring theoretical contents through a concept map, or several linked concept maps, conforming a global knowledge model of the contents seen in class. To help students build the maps, they were given a list with a minimum set of concepts that should appear on their developed maps. Similarly, they were provided with a series of guiding questions that focus the student's attention on the most relevant concepts of the practices. These guiding questions help in turn as focus questions of the developed concept maps. After carrying out the virtual practice, the student must submit a final report of practices exclusively using concept maps, including results and conclusions. Concept maps and procedural models are created with the CmapTools software [22], which allows collaboratively reconstructing them, enables their use in networks, and incorporate them into the developed virtual laboratory platform.

\subsection{Design of the experience and assessment tools}

Research has been developed following a quasi-experimental design with a pilot group consisting of 21 students. The starting aim is to obtain baseline data to carry out later (in the 2013/2014 academic year) a quantitative comparison of the learning amount achieved by students who have used the instructional videos in their laboratory practices through the virtual platform, compared to the amount of learning achieved by students using traditional laboratory practices.

The objective of this stage is to obtain data from two different perspectives:

- A quantitative assessment of the learning achieved by students who have used the instructional videos when performing laboratory practices through the virtual platform.

- A qualitative validation of the technical, instructional and learning aspects of the virtual laboratory created.

For the quantitative study, the teaching methodology employed in the learning process of the students is considered as an independent variable. That is, using virtual laboratories with instructional videos in the practices (teaching methodology of the experimental groups) or using the real laboratory (teaching methodology of the control groups). The dependent variable is the amount of learning achieved by students related to the learning platform used. As assessment tool to quantify the knowledge acquired on the practices, we have developed a questionnaire that the student must answer after completion of each practice.

For the qualitative validation it has been taken into account the opinion of the students, as key participants in the educational process. It has been designed a virtual laboratory evaluation form. The form allows the collection of the views of students in the pilot group using a 5-point Likert scale and 3 additional questions that allow open-ended responses. This information collection tool provides knowledge about the experience and their opinion about the experience carried out. The indicators used in the design of the evaluation form are based on the aspects considered by some authors [23] as quality criteria of materials.

The designed evaluation form comprises the following sections:

1) The first section is referred to functional and usefulness aspects, and consists of 11 items. This section includes indicators to measure: teaching effectiveness, curricular relevance, accessibility, quality of the educational resources employed, and virtual laboratory tutoring through forums and wikis.

2) The second section is based on technical and aesthetic aspects, and consists of 7 items. In this block, we include indicators of the quality of the audio, video, animation, text, content, structure and use of e-learning platform from a technical and aesthetic perspective. 
3) The third section deals with the didactic aspects summarized in 8 items. This section provides information on: user friendliness at university level, motivation capacity (attractiveness, interest), didactic approach (organization, summary...) structured information with correct extension and scientific rigor, didactic effectiveness versus traditional instruction, suitability as a support teaching material for the realization of laboratory practice, or appeal as materials to replace real laboratory practices.

4) The last section is for comments. We ask students their opinion about the advantages of virtual laboratories in relation to other means, and about any problems or inconveniences that may result from their application.

The rating categories established for each of the items and for the overall assessment are:

Excellent: 5 points on a Likert scale; Above average: 4 points on a Likert scale, Average: 3 points on a Likert scale; Bellow average: 2 points on a Likert scale, Extremely Poor: 1 point on the Likert scale.

\section{RESULTS}

The virtual laboratory developed in this work consists of 16 instructional videos on:
1. Light scattering
2. Spectral brightness distribution of an LED
3. LED spectrum through a transmission grating
4. A CD as a reflection lattice
5. Diffraction patterns
6. The Lambert-Beer law with grey filters
7. Fluorescence
8. The Lambert-Beer law with liquids
9. Determination Planck's constant by means of LEDs
10. When is an LED a receiver?
11. Inverse-square law
12. Characterization of a solar cell
13. Determination of the wavelength of the light from an LED
14. UI characteristic of an LED
15. Linear polarization of light
16. Birefringence

Figure 1 shows some screenshots of the instructional videos made. 


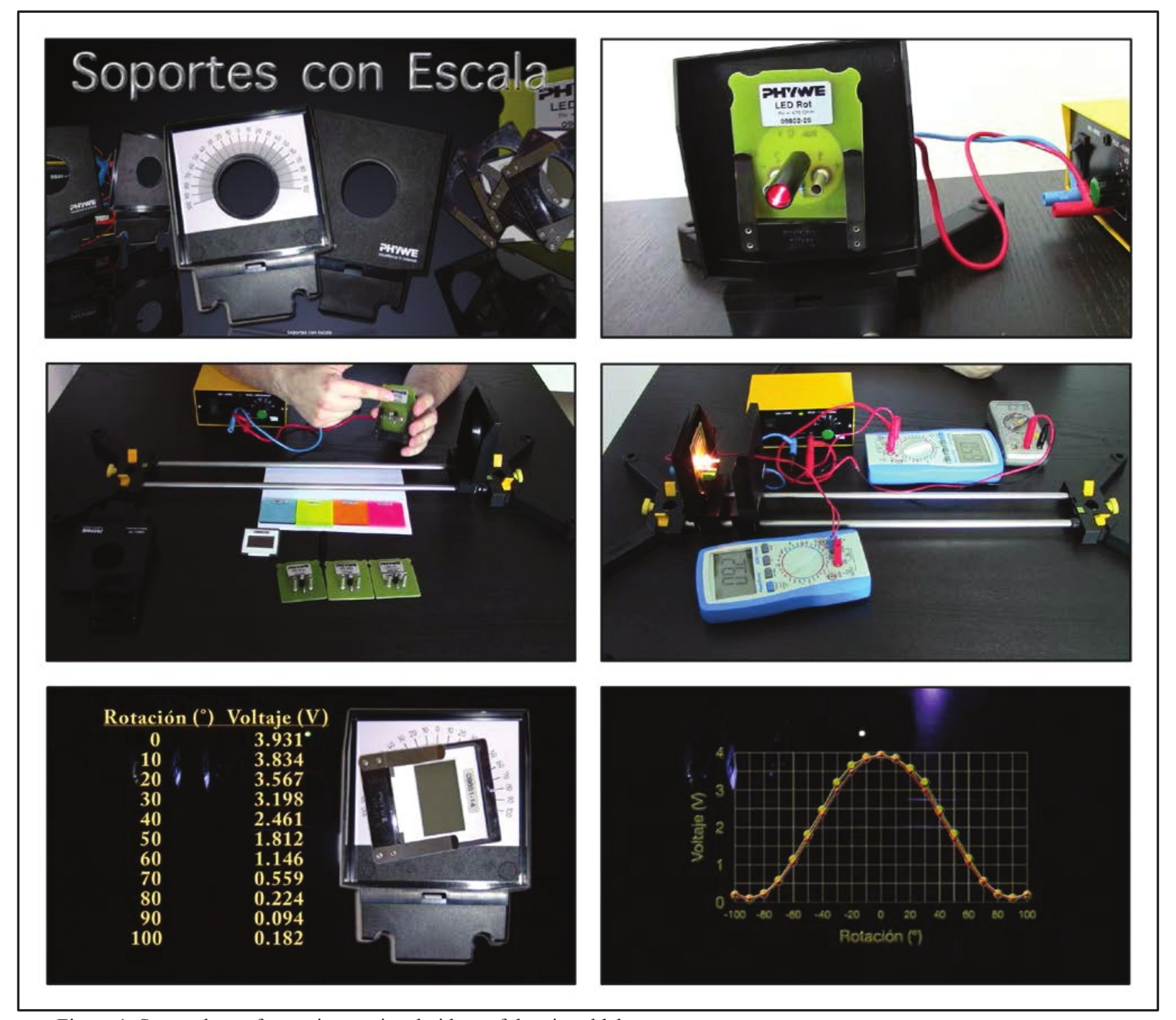

Figure 1. Screenshots of some instructional videos of the virtual laboratory

In order to draw conclusions that serve as a reference for its application in the teaching and learning processes, and to comprehensively validate the work carried out, we show the results obtained with the pilot course. Our goal is to later implement a new corrected version of the virtual laboratory for quantitative validation in the 2013/2014 academic year.

The results obtained from the evaluation forms can be summarized as follows: First, the assessment of the functional aspects by the students in the pilot group has been, overall, very positive. Most of the rated aspects in the form are in the range of "Above average" or "Excellent" quality on the Likert scale. If we make a more specific analysis, the items in this section that have better assessment are those corresponding to the quality of the instructional videos and the quality of the concept map procedural model. These items have been rated as "Excellent" by $52.3 \%$ of students (instructional videos), and $42.8 \%$ of students (procedural models). The item that scored worst is corresponding to the indicator measuring the "accessibility". This could be improved in a future set-up of virtual laboratory.

Concerning the results of the evaluation of the didactic aspects measured in the second section of the evaluation form, we can note that they have been positive. We may highlight, as an example for analysis, two of the items where the student was asked about whether the instructional videos produced could be a supplement for the real laboratory, or even a replacement for it. Thus, $47.6 \%$ believe that these didactic materials are "Excellent" as support material for the 
laboratory. However, only 19\% considered an "Excellent" idea using these materials to replace actual practice. The highest score for this item (33.3\%) was in the "Average" rank. Given these results, it is clear that the main idea is not to replace the traditional practice laboratory, but rather supplement it with the use of the virtual laboratory. However, in the case of distance learning processes through e-learning platforms, where it is not possible to have a real laboratory available, the designed and developed instructional videos can be a fine substitute for the actual experience, and provide students with the same contents achieved in actual practices.

Regarding the assessment of the effectiveness of the developed procedural models, we conducted a quantitative estimation of the value of the concept maps made by the students in the pilot group. To carry out this assessment, we used Novak's method [18]. The score in each of the maps made by the students was compared with values obtained from the guide procedural model made by the teacher. Thus, it was possible to quantify the degree of knowledge that the student had about the proper procedure for the successful completion of the practice. This quantification of the acquired knowledge was obtained from hierarchies, valid relationships, valid and meaningful cross-associations, and examples provided by the students in their procedural models. The scores on the maps have revealed that the integration of these didactic materials in the laboratories leads students to a better understanding of the procedure that takes place in virtual practices.

\section{CONCLUSIONS}

Overall, the results of this research have shown that virtual laboratories created incorporating instructional videos have offered us a useful tool to promote constructivist learning, designed to foster conceptual change by performing virtual practices, organized and sequenced for students to reflect on the information and content they receive. The instructional videos are a virtual guide to the experiment to be performed, which is an advantage for simultaneously carrying out practices when there is little laboratory equipment.

We believe that presenting various formats of audio-visual materials to complement the traditional manual of the practice laboratory may provide students with a better use, since they contain both the theoretical foundation and the development of the practice. In addition, video can add value on a class or a conventional laboratory session. For example, it provides access to experiences and it shows in detail the procedure for performing them. As for the procedural models used, concept maps have helped the students in the process of acquisition of conceptual and procedural content in an organized, sequenced, hierarchical and inclusive way. These procedural models help learning how to proceed in the practices. This virtual laboratory does not encourage the disappearance of the real laboratory, but the integration of both in our teaching practice.

\section{ACKNOWLEDGMENTS}

The authors wish to thank the Regional Government of Extremadura for its financial support through Grant GR10102, partially funded by the European Regional Development Fund.

\section{REFERENCES}

[1] Aceituno, J., Alejandro, C. and Mujica, V., "Propuesta de Sistema de Orientación Integrado para la realización del Laboratorio de Física General, basado en las NTIC", Proc. II Conferencia Internacional de Problemas Pedagógicos de la Educación Superior, (2003).

[2] Alejandro, C., Ruiz, F. and García, M., "Prácticas de laboratorio virtuales de Física", Proc. Memorias de la II Conferencia Internacional de Problemas Pedagógicos de la Educación Superior, (2003).

[3] Rosado, L. and Herreros, J. R., [Internet y Multimedia en Didáctica e Investigación de la Física. Tratado teórico-práctico para profesores y doctorandos], Madrid, UNED (2004).

[4] Zacharia, Z. and Roger Anderson, O., "The effects of an interactive computer-based simulation prior to performing a laboratory inquiry-based experiment on students' conceptual understanding of physics", Am J Phys 71(6), 618-629 (2003). 
[5] Psillos, D. and Niedderer, H., [Teaching and learning in the science laboratory: a book bases on the European project "Labwork in science education"], Dordrecht, Kluwer Academic Publishers (2002).

[6] Finkelstein, N.D., Adams, W. K., Keller, C. J., Kohl, P. B., Perkins, K. K., Podolefsky, N. S. and Reid, S., "When Learning about the Real World is Better Done Virtually". Phys. Rev. ST - PER 1, 010103 (2005).

[7] Martínez, G., Pérez, A.L., Suero, M.I. and Pardo, P.J., [Methodologies, tools and new developments for elearning]. Rijeka, InTech, 169-190, (2012).

[8] Riccioni, A., [Design, Implementation and Evaluation of a Virtual Laboratory for Computer Engineering Education. PhD Dissertation], Università Degli Studi Di Bologna (2010).

[9] Laschi, R. and Riccioni, A., "Design and Implementation of a Virtual Lab for Supporting Students in Modeling, Evaluating and Programming Secure Systems", Proc.of the 13th International Conference on Interactive Computer-Aided Learning (ICL), Villach, Kassel University Press (2008).

[10] Yanitelli, M.S., [Un cambio significativo en la Enseñanza de las Ciencias. El uso del ordenador en la resolución de situaciones experimentales de Física en el nivel universitario básico. PhD Dissertation], Universidad de Burgos (2011).

[11] Salzmann, C., Gillet, D. and Huguenin, P., "Introduction to Real Time Control using labview with an Application to Distance Learning", Int. J. Eng. Educ. 16(3), 255-272 (2000).

[12] Aktan B., Bohus, C., Crowl, A. and Shor, M. H., "Distance learning applied to control Engineering Laboratories", IEEE Trans. Educ., 39, 320-326 (1996).

[13] Candelas, F. A., Torres, F., Gil, P., Ortiz, F., Puente, S. T. and Pomares, J., "Laboratorio Virtual Remoto para Robótica y Evaluación de su Impacto en la Docencia", RIAI, 1(2), 49-57 (2004).

[14] Calvo, I., Marcos, M., Orive D. and Sarachaga I., "Building Complex Remote Laboratories", Comput. Appl. Eng. Educ 18 (1), 53-66 (2009).

[15] Martínez, G., Naranjo, F. L., Pérez, A. L., Suero, M. I. and Pardo, P. J., "Elaboración de videos didácticos de prácticas con láser como material complementario en el laboratorio de óptica para su incorporación en plataformas de m-learning", Proc. XXII Encontro Ibérico para o Ensino da Física, (2012).

[16] Martínez, G., Pérez, A. L., Suero, M. I. and Pardo, P.J., "Implementación de un laboratorio virtual de placas solares fotovoltaicas para el desarrollo de prácticas no presenciales" Proc. The First International Conference on ICT an Education, Lisboa (2010).

[17] Ausubel, D. P., [The Acquisition and Retention of Knowledge: a Cognitive View], Kluwer Academic Publishers, Dordrecht (2000).

[18] Novak, J. D. and Gowin, D. B., [Learning how to learn], Cambridge University Press, Cambridge (1984).

[19] Martínez, G., Pérez, A. L., Suero, M. I. and Pardo, P. J., "The effectiveness of concept maps in teaching physics concepts applied to engineering education: Experimental comparison of the amount of learning achieved with and without concept maps", JOST 22 (2), 204-214 (2012).

[20] Pérez, A. L., Suero, M. I., Montanero, M., Pardo, P. J. and Montanero, M., [Concept maps and conceptual change in physics], Idea Group Publishing, New York (2010).

[21] Martínez, G., Pérez, A. L., Suero, M. I. and Pardo, P. J., "Modelos de procedimientos creados mediante mapas conceptuales. Concreción a una práctica de laboratorio de óptica", Proc. of the Fifth Int. Conference on Concept Mapping 2, 361-368 (2012).

[22] http://ihmc.us

[23] Morales, E., García, F., Moreira, T., Rego, H. and Berlanga, A., "Units of learning quality valuation”, Revista de Educación a Distancia, 1-8 (2005). 